\section{Sarcoidosis or Crohn's Disease?}

\author{
R. B. CLAGUE
}

British Medical fournal, 1972, 3, 804

Many authors (Hadfield, 1939; Watson et al., 1945; Cowdell, 1954) have suggested a possible relation between sarcoidosis and Crohn's disease. The possibility has arisen again recently with new evidence from Mitchell et al. (1970), although Siltzbach et al. (1971) contest this. The present case is of interest in this context.

\section{Case Report}

A 36-year-old housewife first presented in 1961 with bilateral parotid swellings accompanied by loss of weight and shortness of breath. She had a generalized lymphadenopathy and a clinical diagnosis of sarcoidosis was made, which was suggested by the radiographic appearances in the chest. She was treated with prednisone, which produced a rapid resolution of the parotid swelling, but the chest radiograph did not become clear until two and a half years later. The prednisone dosage was then tailed off.

One year later she began to have episodes of vague epigastric pain with vomiting and subsequently developed a megaloblastic anaemia, with tingling and numbness in the legs. The plasma vitamin $B_{12}$ level was $70 \mathrm{pg} / \mathrm{ml}$. A diagnosis of pernicious anaemia with subacute combined degeneration of the cord was made, and she was successfully treated with cyanocobalamin injections.

She was admitted to hospital eight months later with a fourmonth history of severe epigastric pain and vomiting. The pain was colicky in nature and the vomiting, which was projectile, occurred after most meals. She had lost nearly 3 stone $(19 \mathrm{~kg})$ in weight. She had no haematemesis or melaena. On examination there was slight epigastric tenderness but no other abnormality.

The haemoglobin level was $100 \%$ and the W.B.C. $3,600 / \mathrm{mm}^{3}$; a blood film was normal. The erythrocyte sedimentation rate was $4 \mathrm{~mm}$ in one hour. The blood urea and electrolyte levels were within normal limits. The chest radiograph was normal, with clear lung fields. Tests for occult blood in the stools were negative on two occasions but strongly positive on a third. A histamine test meal showed complete achlorhydria. Gastric cytology was normal. A barium-meal examination showed free oesophageal reflux, with no hiatus hernia, and atrophic gastritis. It was difficult to be sure that the prepyloric area was normal, and a neoplasm could not be excluded. There was a narrowed, deformed duodenal cap consistent with chronic duodenal ulceration. Gastroscopy showed a red, inflamed mucosa, but no satisfactory view of the pyloric region was obtained.

At laparotomy a large stomach with mild hypertrophy was seen. The first part of the duodenum was thickened, and the peritoneal coat looked bright red, with multiple small pale, pin-head, granular lesions on it. Similar lesions were found in three segments of the lower ileum, each about $8-10 \mathrm{~cm}$ long, with intervening lengths of $16-30 \mathrm{~cm}$ of normal-looking intestine. Biopsy specimens were taken from one of these lesions and the stomach, and the abdomen was then closed. No other evidence of abdominal disease was found.

Histological examination showed masses of sarcoid follicles distributed throughout the whole thickness of the intestinal wall. These follicles contained Langhans cells and giant cells of the foreign body type, but there was no evidence of caseation (see Photograph). There was a relative lack of lymphocytes and a thin submucosa. The mucosa was intact. There were no such follicles in the stomach.

Royal Victoria Infirmary, Newcastle upon Tyne

R. B. CLAGUE, M.B., B.s., Senior House Officer, Department of Rheumatology

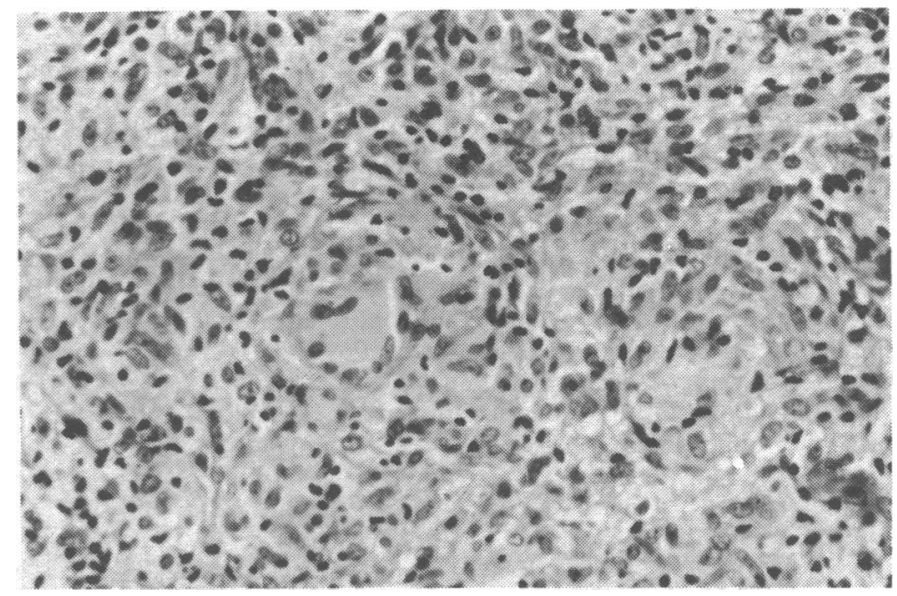

Section of wall of small intestine showing sarcoid follicle. $(\times 247$.

The patient responded dramatically to treatment with prednisone, having a total remission of her symptoms and a weight gain of 2 stone $(12.7 \mathrm{~kg})$ in three months.

\section{Comment}

The histological appearances in this patient were the same as those described by Watson et al. (1945) in two patients with "isolated sarcoidosis of the small intestine simulating nonspecific ileojejunitis." Similar cases were also reported by Hadfield (1939) and Cowdell (1954) suggesting a possible relation between sarcoidosis and Crohn's disease. Phear (1958) and Scadding (1967), however, denied any such relation as they were unable to find any evidence of generalized sarcoidosis in about 100 cases of Crohn's disease. The present patient also had no evidence of generalized sarcoidosis at the time when the intestinal lesions were investigated, but she had a past history of sarcoidosis.

Controversy has been aroused again recently. The delayed hypersensitivity reactions are known to be similar in the two diseases and Mitchell et al. (1970) reported that the Kveim test, which is positive in $84 \%$ of cases of active sarcoidosis (Siltzbach, 1961), was positive in $51 \%$ of a series of cases of Crohn's disease. Siltzbach et al. (1971), however, have found the Kveim test to be uniformly negative in Crohn's disease, which confirms a previous report by Williams (1965). Unfortunately, in the present case no Kveim test was done. It is therefore uncertain whether this case and the other similar cases reported should be regarded as Crohn's disease with an unusually sarcoid-like histology or as sarcoidosis of the small intestine.

I wish to thank Mr. E. P. Kempsey, consultant surgeon at Ryhope General Hospital, for allowing me to report this case; Dr. D. A. Leslie, consultant pathologist at the Royal Infirmary, Sunderland, and Dr. J. Watson, consultant pathologist at the Royal Victoria Infirmary, Newcastle upon Tyne, for their careful histological evaluation; and Professor I. D. A. Johnston, of the department of surgery, University of Newcastle upon Tyne, and Mr. C. W. Venables, consultant surgeon at the Royal Victoria Infirmary, for their helpful advice.

\section{References}

Cowdell, R. H. (1954). Quarterly fournal of Medicine, 23, 29.

Hadfield, G. (1939). Lancet, 2, 773 .

Mitchell, D. N., Cannon, P., Duer, N. H., Hinson, K. F. W., and Willoughby, J. M. T. (1970). Lancet, 2, 496

Phear D. N (1958), Lancet, $2,1250$.

Scadding, J. G. (1967). Sarcoidosis. London, Eyre and Spottiswoode.

Scadding, J. G. (1967). Sarcoidosis. London, Eyre and Spottiswoode. 476 Siltzbach, L. E. (1961). Fournal of the American Medical Association, 178, 476. (1971). Lancet, 2, 634.

Watson, C. J., Rigler, L. G., Wangensteen, O. H., and McCartney, J. S. (1945). Gastroenterology, 4, 30. Williams, W. J. (1965). Gut, 6, 503. 